\title{
Continuidades y discontinuidades de la movilidad ocupacional en México*
}

\author{
René Zenteno** \\ Patricio Solís***
}

En este artículo se analizan las tendencias de la movilidad ocupacional en el México urbano a partir de los datos de la Encuesta Demográfica Retrospectiva (Eder). Para ello se toman como referencia los hallazgos de un estudio previo realizado en Monterrey, en donde fueron identificadas dos tendencias: la continuidad de la movilidad estructural ascendente y la creciente desigualdad de logros ocupacionales asociada a los orígenes sociales de los individuos. Los resultados muestran que en términos generales estas tendencias también se observan en el conjunto de las ciudades del país, aunque con algunos matices que no se aprecian en Monterrey; revelan también que las transformaciones económicas y sociales experimentadas en el país durante las últimas décadas han producido efectos negativos en la movilidad social pues, a pesar de la continuidad en la movilidad estructural, se ha acentuado la inequidad de oportunidades laborales.

Palabras clave: movilidad social, desigualdad, trabajo, Monterrey. Fecha de recepción: 24 de julio de 2005.

Fecha de aceptación: 9 de enero de 2006.

\section{Continuities and Discontinuities in Occupational Mobility in Mexico}

This article analyzes the trends in occupational mobility on the basis of data from the Retrospective Demographic Survey (Eder). To this end, it used the findings of a previous study conducted in Monterrey that identified two trends: the continuity of rising structural mobility and the growing inequality of occupational achievements associated with individuals' social origins. The results show that in general terms, these trends can also be observed in the country's cities as a whole, although with certain nuances not found in Monterrey. They also show that the social and economic transformations experienced in the country in recent decades have produced negative effects on social mobility, since despite the continuity in structural mobility, the inequality of job opportunities has been exacerbated.

Key words: social mobility, inequality, work, Monterrey.

* Agradecemos a Julio Escobedo el apoyo que nos brindó para la realización de este trabajo, así como las excelentes observaciones de los dictaminadores anónimos.

** Profesor investigador de la Escuela de Graduados en Administración Pública y Política Pública del ITESM campus Monterrey. Correo electrónico: rzenteno@itesm.mx. *** Profesor investigador del Centro de Estudios Sociológicos de El Colegio de México. Correo electrónico: psolis@colmex.mx.

ESTUDIOS DEMOGRÁFICOS Y URBANOS, VOL. 21, NÚM. 3 (63), PP. 515-546 


\section{Introducción}

Los años sesenta y principios de los setenta fueron testigos de significativos avances de los estudios de estratificación social en buen número de los países capitalistas. México no fue la excepción. A partir de los estudios de las ciudades de Monterrey (Balán, Browning y Jelin, 1977) y México (Muñoz, Oliveira y Stern, 1977; Contreras Suárez, 1978), un consolidado grupo de sociólogos y demógrafos dedicó sus labores al análisis sistemático de los procesos de cambio que en aquel entonces daban forma a una nueva estructura de clases y estratificación social en el país: transformación económica y sociopolítica del campo mexicano, rápida industrialización y urbanización, intensa migración del campo a la ciudad, expansión de los servicios educativos y de salud, entre muchos otros. Estas investigaciones marcaron un hito al inyectar una mayor perspectiva sociológica a los estudios demográficos e iniciar la tradición científica que hoy conocemos como sociodemografía (Coubes, Zavala y Zenteno, 2005). El repentino vuelco de las ciencias sociales al análisis de las secuelas de la crisis económica de los años ochenta implicó una discontinuidad del impulso inicial marcado por los estudios de Monterrey y de la Ciudad de México, como bien ha sido expuesto por Escobar (2001).

En los últimos 25 años la economía y la sociedad mexicanas se han transformado significativamente. Desde una perspectiva económica, el país ha pasado de un modelo económico basado en el fortalecimiento del mercado interno vía la sustitución de importaciones a un esquema de franca apertura económica y comercial hacia el exterior. La agricultura y la manufactura dejaron de ser los motores de la economía nacional para dar paso al comercio y los servicios como principales fuentes de empleo de los mexicanos. Esta transición, como es de sobra conocido, se ha traducido en costos elevados para la clase trabajadora del país, que ha debido enfrentar no sólo una disminución real en el poder adquisitivo de sus ingresos, sino también un claro deterioro en sus condiciones de empleo en lo que a protección social se refiere. En este lapso las mujeres se incorporaron al mercado de trabajo a una velocidad nunca antes vista en la historia moderna del país. Desde una perspectiva demográfica, los niveles de fecundidad han disminuido de manera impresionante; la migración mexicana hacia Estados Unidos se ha vuelto un fenómeno nacional que ha definido nuevos y más complejos vínculos sociales, económicos y culturales entre ambos países; la población del país continúa concentrándose cada vez más en las 
áreas metropolitanas, y la migración interna se dirige de manera creciente hacia el norte, donde los empleos crecen más rápidamente como resultado de la nueva industrialización orientada hacia el exterior. Desde una perspectiva social, México cuenta hoy día con una población menos analfabeta, más escolarizada y más cosmopolita. La ciudadanía también ha dado pasos importantes en la búsqueda de una mayor participación política en la incipiente democracia mexicana.

Aunque regido por las mismas necesidades e instituciones, México es un país con una estructura económica y social muy distinta de la que tenía en los años sesenta. Conocer los efectos del desarrollo económico y social más recientes sobre el curso de vida de su población constituye nuevamente el objetivo central de las investigaciones sociodemográficas en México. ${ }^{1}$ Este renovado interés ha sido posible, entre otras razones, gracias a la reciente disponibilidad de información longitudinal que facilita el entendimiento cabal de los procesos de cambio a la luz de las trayectorias individuales o familiares. ${ }^{2}$

Un asunto central en los estudios de estratificación social y curso de vida, particularmente en una sociedad tan desigual como la mexicana, es la movilidad social. Los estudios contemporáneos sobre el tema, que se enfocan principalmente en la movilidad ocupacional, suelen interesarse por dos facetas de este fenómeno. La primera se relaciona con el grado de movilidad social que se genera en una sociedad determinada como resultado de los cambios globales en las estructuras de oportunidades. Este tipo de movilidad, a la que suele denominarse "estructural" o "absoluta", se manifestó en el caso mexicano por las amplias transformaciones de la estructura ocupacional que se generaron durante el curso de rápida urbanización e industrialización que se desarrolló hasta principios de los años ochenta.

La segunda faceta se relaciona con el proceso de estratificación social, es decir, con la transmisión de las ventajas y desventajas sociales de una generación a otra. Más allá de que se logre o no incrementar la movilidad absoluta, una premisa fundamental de las sociedades democráticas modernas es garantizar la equidad en el acceso a las oportunidades, ya sea mediante el acceso universal a la educación o por medio de las políticas sociales. Es posible evaluar hasta qué punto

${ }^{1}$ Véase por ejemplo la serie de trabajos editados por Coubes, Zavala y Zenteno (2005) y las investigaciones de Solís $(2002,2005)$ en la ciudad de Monterrey.

${ }^{2}$ En términos generales la información de corte longitudinal es más adecuada para realizar análisis explicativos, pues la información de corte transversal no ofrece la posibilidad de examinar el cambio de las variables causales en el tiempo (Tuma y Hannan, 1984; Blossfeld y Rohwer, 2002). 
se cumple con este ideal al obtener medidas de movilidad "de circulación" o "relativa", es decir, al contrastar las oportunidades de movilidad social ascendente entre individuos que provienen de distintos estratos sociales.

Como se dijo antes, durante las décadas de los sesenta y setenta se realizaron estudios que permitieron identificar los patrones de movilidad social en México durante la industrialización por sustitución de importaciones. No obstante, pocos esfuerzos sistemáticos recientes han contribuido a entender los cambios en la movilidad social -tanto estructural o absoluta como relativa- asociados a las transformaciones económicas y sociales del último cuarto de siglo. Uno de estos trabajos es el estudio de Solís (2002) para la ciudad de Monterrey. Dos de sus conclusiones fueron las siguientes:

1) La continuidad en las altas tasas de movilidad estructural ascendente de tipo intergeneracional, asociada a los cambios en la economía y el mercado de trabajo, dio un mayor brío al comercio y los servicios frente a las actividades industriales.

2) El incremento de la importancia de variables asociadas al origen social como determinantes de la posición ocupacional de los individuos denota la permanencia e incluso el incremento en tiempos recientes de las amplias inequidades sociales en el acceso a las oportunidades laborales.

¿Qué tan generalizables son estos resultados para el conjunto nacional urbano? ¿En qué medida las tendencias de la movilidad ocupacional observadas en Monterrey corresponden a las del resto de las grandes ciudades del país? La realización del presente trabajo fue motivada por el interés en dar respuesta a estas preguntas. El momento era oportuno dada la disponibilidad de los datos de la Encuesta Demográfica Retrospectiva (Eder), la cual recolectó historias de vida (migratoria, ocupacional y familiar) de una muestra probabilística de la población nacional perteneciente a las cohortes de nacimiento 19361938, 1951-1953 y 1966-1968. Por razones que se explican más adelante, nuestro análisis se enfocó únicamente a la población masculina urbana.

Nuestros resultados muestran que los padres de las cohortes nacionales fueron gratificados ampliamente por las oportunidades ocupacionales de los mercados de trabajo urbano, a pesar de sus orígenes rurales. Las transformaciones de la economía mexicana durante la 
segunda mitad del siglo Xx facilitaron una mayor inserción de sus hijos en ocupaciones no manuales y, por lo tanto, posibilitaron la movilidad ocupacional ascendente. Sin embargo la sociedad y la economía urbanas del país no dispensaron a los hijos oportunidades ocupacionales tan amplias como las observadas en Monterrey. Las diferencias en las tasas de movilidad entre Monterrey y el conjunto nacional urbano se asocian principalmente a los cambios en las estructuras ocupacionales de padres e hijos (esto es, a la movilidad estructural propiamente dicha), y no a una mayor rigidez o fluidez en la transmisión intergeneracional de posiciones ocupacionales. Aun en los años de reestructuración y crisis económicas, las cohortes más jóvenes experimentaron movilidad intergeneracional ascendente tanto en el ámbito nacional urbano como en Monterrey. Finalmente, el análisis estadístico revela que hubo una mayor inequidad social en el acceso a las oportunidades laborales entre la población de las áreas urbanas del país, tal y como fue observado para el caso de Monterrey.

Este texto se divide en cuatro secciones. La primera presenta un resumen de las investigaciones más recientes sobre el tema de la movilidad social en México; se intenta destacar principalmente los hallazgos en relación con la movilidad estructural ascendente y con el peso del origen social en la explicación de este tipo de movilidad. Posteriormente se describen las fuentes de información que sustentan esta investigación, así como algunas cuestiones metodológicas relevantes para la comparación adecuada de los datos de la Eder y los correspondientes a las encuestas de Monterrey. Las siguientes dos secciones constituyen el análisis empírico de las tablas de movilidad y los efectos de los orígenes sociales, respectivamente.

\section{Investigaciones recientes sobre movilidad ocupacional en México}

Dado que en México la vía más común de acceso a ingresos monetarios es el mercado de trabajo, las condiciones de vida de la mayoría de la población, así como su estatus social, están básicamente determinados por el tipo de empleo que se desempeña. Los estudios más recientes sobre la movilidad social en México coinciden en que una de las características sobresalientes de las grandes ciudades mexicanas antes de los años ochenta fue que se ofrecían oportunidades abundantes para la movilidad social. El proceso de industrialización vía la sustitución de 
importaciones abrió las puertas del mercado laboral a la gran mayoría de los sectores menos educados de la población, lo que originó una estructura ocupacional relativamente abierta, con peldaños accesibles para el ascenso social (Escobar, 2001; Cortés y Escobar, 2003; Parrado, 2005; Solís, 2005). Sin duda había muy poca incertidumbre en las familias en torno al futuro de los hijos, pues se creía que éstos tendrían mayores oportunidades para transformar positivamente sus condiciones de vida. Incluso para la población agrícola este optimismo era una característica constante debido a que los procesos de migración interna (rural urbana) significaban un impulso en la escalada social (Escobar, 2001). De esta manera nadie podía anticipar que, a partir de los años ochenta, las principales ciudades mexicanas se verían sacudidas por severas crisis y profundas reformas económicas y un proceso marcado de terciarización e informalidad económica. ¿Hasta qué punto estas transformaciones han afectado las oportunidades de movilidad social en México? La literatura revisada en esta sección ha intentado responder a esta pregunta a partir de distintas aproximaciones.

Con el objeto de observar las particularidades de la inequidad social en México, trabajos recientes se han inclinado por estudiar los logros ocupacionales, la desigualdad en el acceso a los diversos estratos socioocupacionales y la movilidad laboral intergeneracional o intrageneracional. El empleo y sus categorías se han convertido en el marco de referencia de las investigaciones sobre estratificación y movilidad social, ya que el mercado de trabajo constituye, comúnmente, el mecanismo fundamental para la asignación de activos en las distintas facetas de la estratificación (Solís, 2005).

El cuadro 1 muestra una síntesis de siete investigaciones recientes que han abordado el asunto de la movilidad social u ocupacional en México. Debido a que los resultados de estos estudios son muy amplios, el propósito del cuadro es destacar en forma resumida sus conclusiones en relación con las cuestiones de interés de este texto: la movilidad ascendente y la influencia del origen o adscripción social sobre el logro ocupacional. Además, se incluye información metodológica relevante de cada una de estas investigaciones.

Dos de estos estudios fundamentaron su análisis empírico en la información recolectada por el módulo "Género, edad, familia y trabajo en el México urbano", incluido y administrado en la Encuesta Nacional de Empleo Urbano (ENEU) del INEGI en 1994. Este módulo se aplicó a una muestra aleatoria de las ciudades de México, Guadalajara, Monterrey, Mérida, Veracruz y Córdoba-Orizaba. En el primero 


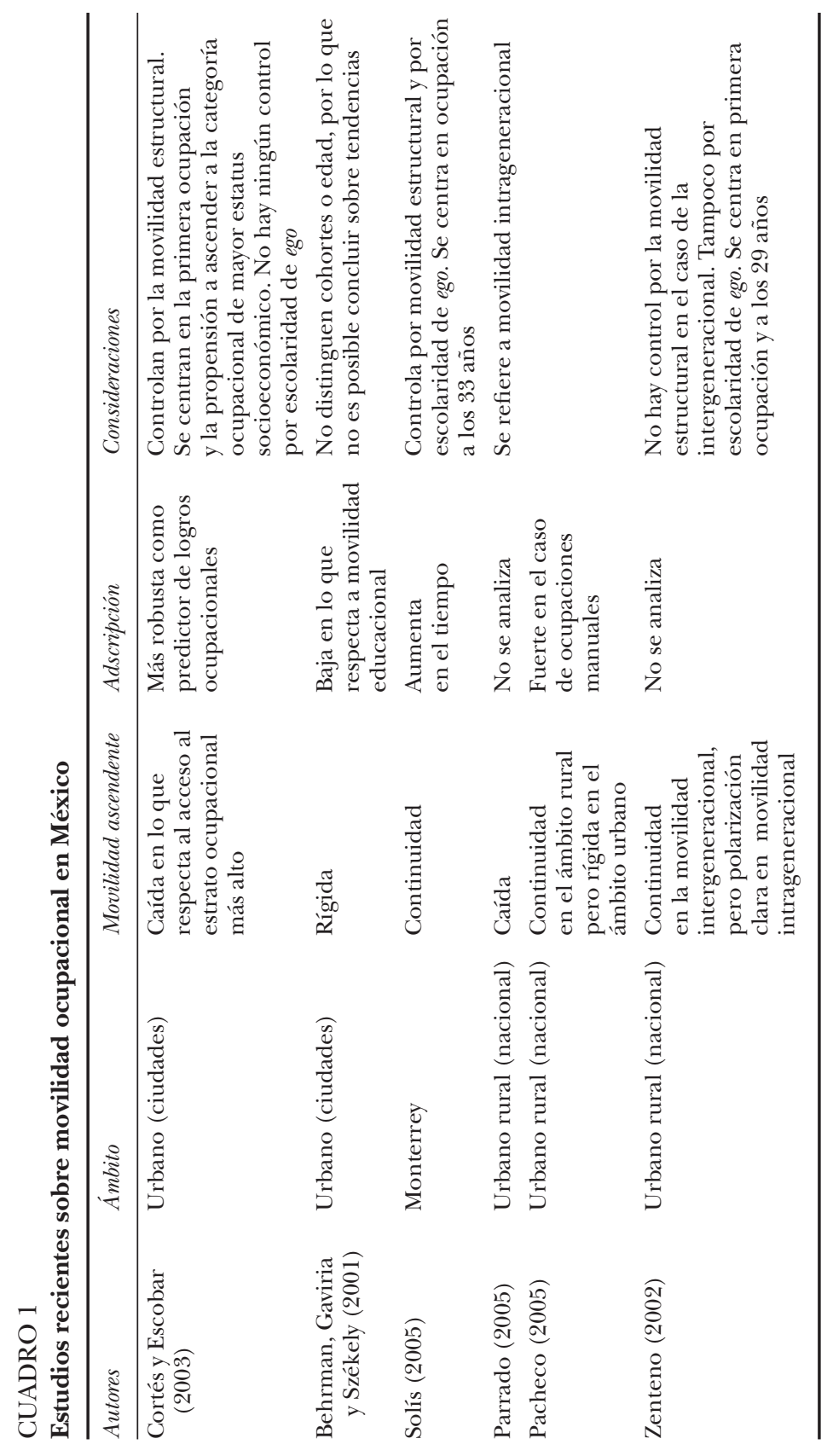


de ellos Behrman, Gaviria y Székely (2001) realizaron un estudio comparativo de la movilidad social intergeneracional en América Latina; para ello analizaron las características educativas y ocupacionales de la estratificación social. Sus principales aportaciones tienen que ver más con las diferencias educativas, absolutas y relativas, entre padres e hijos, y menos con la movilidad ocupacional. Estos autores encontraron que en México, al igual que en el resto de América Latina, los hijos tienden a sobrepasar el nivel educativo de sus padres. A pesar de ello la movilidad educativa de la sociedad mexicana se clasifica como moderada respecto a sus similares latinoamericanos. Este estudio también incluyó un análisis por cohortes (grupos de edad), el cual pretendió explorar la conexión entre los grados de educación y los cambios en la movilidad social de dichos grupos. Al igual que Brasil y Colombia, México muestra un patrón de rendimientos marginales decrecientes a la educación. Además, México es el único país donde la inmovilidad escolar se incrementa ligeramente entre las cohortes más recientes.

Aun siendo moderada la movilidad educativa, la estratificación ocupacional es aún más rígida en México (Behrman, Gaviria, Székely, 2001). Los autores afirman que la probabilidad de que una persona tenga una ocupación de cuello blanco (no manual) en México es 3.5 veces más alta cuando cuenta con un padre cuya ocupación es similar que cuando se tiene uno que labora en una ocupación de cuello azul (manual). Según sus resultados, México presenta una de las tasas de movilidad ocupacional más bajas del continente americano. A diferencia del análisis de la educación, el estudio de los logros ocupacionales no incluyó ninguna diferenciación por cohortes o edades, por lo que no fue posible concluir sobre tendencias.

Otro estudio basado en el módulo "Género, edad, familia y trabajo en el México urbano" de la ENEU fue publicado por la CEPAL con la autoría de Fernando Cortés y Agustín Escobar (2003). Este trabajo analiza la movilidad intergeneracional en tres periodos: antes de 1982, de 1982 a 1988, y después de $1988 .{ }^{3}$ A diferencia de otras investigaciones que se interesan por la movilidad ascendente a lo largo de toda la estructura ocupacional, Cortés y Escobar sólo calculan los momios de llegar al estrato más alto de la jerarquía, el de los patrones de empresas grandes, profesionistas y funcionarios públicos de alto nivel. En este

${ }^{3}$ Los periodos son representativos de los distintos contextos económicos que el país vivió durante los últimos cuarenta años: industrialización por sustitución de importaciones (antes de 1982), modelo de transición o economía mixta (de 1982 a 1988) y reestructuración económica (después de 1988). 
sentido, los autores concluyeron que ha existido un marcado deterioro de las oportunidades de ascender o permanecer en la categoría ocupacional de mayor jerarquía a partir de 1988.

La única excepción a esa tendencia fue observada en los originarios de la tercera categoría ocupacional (patrón chico y no profesional), entre quienes el descenso es menos marcado. Esta caída de oportunidades de logro, sin embargo, no se relaciona directamente con la transición económica, ya que, mientras el crecimiento económico se estancó en 1982, las limitaciones de ascender sobrevinieron en 1988. ${ }^{4}$ Así, el estrechamiento relativo de las oportunidades de logro disminuye en las tres primeras categorías ocupacionales, se mantiene constante en la cuarta categoría, y se fortalece en las inferiores (Cortés y Escobar, 2003). Quizás uno de los resultados más interesantes de esta investigación se dio a partir del análisis de índices entrópicos realizado por los autores, pues mostró que la dispersión de los individuos de cada categoría en la estructura ocupacional es cada vez menor o más pequeña. Por ende, hay una menor fluidez ocupacional, lo que provoca una mayor rigidez en el sistema de estratificación ocupacional en México.

En su artículo "La movilidad ocupacional de los hijos frente a sus padres”, Edith Pacheco (2005) analizó las formas en que los diferentes estatus socioeconómicos de origen de los individuos estructuran distintas inserciones en el mercado laboral. Este estudio tiene como fuente de datos la Eder de 1998, con la cual la autora intenta indagar los conceptos de herencia ocupacional bruta y neta. ${ }^{5}$ Pacheco analiza las tres cohortes de individuos entrevistadas en esta encuesta (19361938, 1951-1953, y 1966-1968) y estudia su movilidad intergeneracional. Dadas las complejidades teóricas y analíticas que dificultan el estudio de la movilidad social de las mujeres, su investigación se centró sólo en la población masculina. Pacheco concluyó que en los contextos rurales el cambio en las estructuras ocupacionales se produjo entre la segunda y la tercera cohorte, mientras que en los ámbitos urbanos se presentó entre la primera y la segunda cohorte. Además, apreció una mayor movilidad ocupacional ascendente en los contextos urbanos. La herencia neta ocupacional se presentó con mayor intensidad en el

\footnotetext{
${ }^{4}$ Aunque habría que advertir que tal descenso en las oportunidades de alcanzar el estrato más alto de la jerarquía coincide con la liberalización de la economía nacional en el año de 1988.

${ }^{5}$ La herencia bruta ocupacional se refiere a la resistencia al nivel ocupacional de la anterior generación, reconociendo que los procesos estructurales condicionan la demanda de mano de obra. La herencia neta ocupacional, por otra parte, significa la permanencia en la misma ocupación que los padres (Pacheco, 2005).
} 
ámbito rural, pero en el urbano se observó que la capacidad de abandonar o resistir al nivel ocupacional de la generación anterior se expresa especialmente en las ocupaciones ubicadas en los extremos de la estructura laboral. La relación entre la ocupación del padre y la del hijo está medida por el tipo de localidad geográfica y la cohorte de nacimiento. Finalmente, la autora argumenta que la educación es la variable que más explica la probabilidad de encontrarse en ocupaciones no manuales, aunque en el caso de las manuales, la ocupación del padre se convierte en el factor de mayor explicación.

Emilio Parrado (2005), en su estudio titulado "Economic Restructuring and Intra-Generational Class Mobility in Mexico", utiliza también los datos de las Eder y es en el único de todos los estudios revisados en que se analizan los efectos de la reestructuración económica de los años ochenta sobre la movilidad intrageneracional en México. De acuerdo con este autor, a diferencia del periodo de industrialización por sustitución de importaciones, el nuevo contexto económico ha incidido negativamente en el logro de permanecer en la misma categoría ocupacional de la clase profesional. Esto desmitifica la explicación neoliberal de la desigualdad, que la define como el incremento de la demanda de trabajadores calificados en un contexto de liberalización comercial y cambio tecnológico. En ese sentido los miembros de la cohorte más joven son menos propensos, en comparación con los de la cohorte intermedia, a entrar al mercado laboral valiéndose de la clase profesional, por lo que su estatus social depende de la experiencia y el nivel de educación con que cuenten (Parrado, 2005). No obstante, asegura el autor, la educación ha dejado de ser un factor determinante en la prevención de la movilidad descendente, es decir, los altos niveles de educación ya no aseguran la entrada ni la permanencia en los estratos más altos de la estructura ocupacional. El liberalismo económico, por lo tanto, ha favorecido la entrada de muchos jóvenes a la clase informal. El estancamiento de la movilidad social, en general, se ha convertido en una constante de la sociedad mexicana.

El último trabajo, de Patricio Solís, trata sobre el cambio estructural y la movilidad ocupacional en Monterrey. Esta investigación es relevante no sólo porque recopiló información específica para estudiar estos fenómenos, sino también porque se centra en una de las ciudades con mayor dinamismo económico del país. Para ello, además de la Encuesta Nacional de Empleo Urbano, Solís analiza dos encuestas retrospectivas: la Encuesta sobre Movilidad Social y Geográfica en Monterrey, realizada por Browning, Balán y Jelin en 1965, y la Encuesta sobre Mo- 
vilidad Social y Curso de Vida en Monterrey, efectuada a finales del año 2000. Esta última encuesta se llevó a cabo exclusivamente para comparar los datos sobre movilidad social con los de 1965. Tales encuestas, debido a su carácter retrospectivo, permitieron realizar el análisis sobre movilidad ocupacional en Monterrey a lo largo del siglo Xx, ${ }^{6}$ abarcando los distintos periodos de desarrollo económico del país. Al contrastar las trayectorias ocupacionales de los hombres de Monterrey con las observadas en 1965, se puede analizar de qué manera las transformaciones económicas y contextuales han alterado los patrones de movilidad social y, además, saber si las oportunidades de ascenso ocupacional han declinado o no en relación con el pasado (Solís, 2005). Los cambios estructurales que experimentó Monterrey a finales de los setenta, por ejemplo, se han traducido en cambios en la composición del mercado laboral que han facilitado la movilidad estructural ascendente. Es decir, jóvenes provenientes de familias obreras pudieron cristalizar sus aspiraciones de alcanzar trabajos no manuales (Solís, 2005).

La continuidad de la movilidad estructural ascendente debe tomarse con bastante precaución. Por un lado, porque el grueso de las nuevas ocupaciones no manuales se concentra en actividades de baja calificación, particularmente como comerciantes y vendedores. Aun en un mercado de trabajo como Monterrey, los profesionistas, gerentes y técnicos especializados no conforman una mayoría entre quienes desempeñan ocupaciones no manuales. Por otro lado, el nuevo contexto económico también ha producido una marcada caída de los ingresos laborales no manuales en la capital regiomontana. Esto quiere decir que la movilidad ascendente hacia los estratos no manuales es hoy menos redituable económicamente que en el pasado. Si bien los jóvenes de ahora ascienden en la estructura laboral, tienen altas probabilidades de obtener ingresos similares o inferiores a los de sus padres (Solís, 2005). La inequidad social en el acceso a las oportunidades laborales asociada a la clase social de origen o los antecedentes familiares se ha visto incrementada. De este modo, pese al éxito industrial de la ciudad de Monterrey durante gran parte del siglo Xx, no ha escapado de los efectos negativos de las transformaciones económicas.

Aunque con diferentes matices, y a pesar de sus discrepancias metodológicas, los trabajos revisados en este apartado tienden a resal-

${ }^{6}$ Solís realiza un análisis de la movilidad ocupacional en Monterrey con datos que incluyen un amplio rango de cohortes de nacimiento (1905-1969), lo que permite obtener medidas de movilidad para los periodos del desarrollo estabilizador y de la liberación económica. 
tar que el panorama de la movilidad social en México no es tan desolador como pudiera haberse esperado en un contexto de crisis económica y reestructuración. A pesar de ello, casi todos tienden a tomar precauciones en relación con dos factores. Por un lado, que la movilidad ocupacional continúa pero tiende a ser más polarizada y, probablemente, menos vinculada a la mejora en las condiciones de vida. Por el otro, que los orígenes sociales de los individuos tienden a ser un determinante cada vez más importante del logro ocupacional, lo que denota un incremento de la inequidad social en el acceso a las oportunidades laborales.

\section{Datos y metodología}

La información nacional que se utiliza en este análisis proviene de la Encuesta Demográfica Retrospectiva (Eder) dirigida por Marie Laure Coubes, Gabriel Estrella, María Eugenia Zavala y René Zenteno. ${ }^{7} \mathrm{La}$ Eder ha sido la primera encuesta de historias de vida representativa del ámbito nacional en México. Su principal objetivo fue recolectar información individual sobre la naturaleza temporal de los procesos sociales y demográficos que experimentó México durante la segunda mitad del siglo Xx, así como sobre las interrelaciones de los distintos fenómenos demográficos en las trayectorias de vida de las personas.

La población objetivo de la Eder correspondió a las cohortes que nacieron en los años 1936 a 1938, 1951 a 1953 y 1966 a 1968. Sus integrantes tenían en 1998, al momento de levantarse la encuesta, 60 a 62, 45 a 47 y 30 a 32 años de edad, respectivamente. La separación de quince años entre dichas cohortes permitió entrevistar a grupos de personas que transitaron a su vida adulta en entornos económicos, sociales y demográficos muy variados, los cuales pudieron tener influencias particulares sobre las transiciones migratorias, laborales y

${ }^{7}$ La realización de esta encuesta fue posible gracias al apoyo financiero otorgado por instituciones mexicanas, francesas y estadunidenses. El auspicio más importante provino del Consejo Nacional de Ciencia y Tecnología por medio del proyecto de investigación "Estudio demográfico retrospectivo: movilidad, empleo y familia" (Conacyt 25809-D). A este financiamiento se agregaron las aportaciones de la Universidad Autónoma de Baja California (UABC), la Universidad de Pennsylvania y, por la parte francesa, del Centro Francés sobre la Población y el Desarrollo (CEPED), el Centro de Investigación y Documentación para América Latina (CREDAL) y la Universidad de París X-Nanterre. Igualmente importantes fueron los apoyos institucionales proporcionados a los responsables del proyecto por parte de El Colegio de la Frontera Norte, el Instituto Tecnológico y de Estudios Superiores de Monterrey y la UABC. 
familiares de las mismas. ${ }^{8}$ Para los fines de este trabajo es importante destacar los periodos en que los miembros de cada cohorte vivieron sus trayectorias laborales hasta los 29 años, que será el punto de referencia para captar la ocupación del entrevistado. Así, como se aprecia en la gráfica 1, las trayectorias laborales de los miembros de la cohorte 1936-1938 transcurrieron enteramente durante el auge de la sustitución de importaciones, aproximadamente entre 1951 y 1967; las de los nacidos entre 1951-1953 tuvieron lugar al final del periodo de sustitución de importaciones y culminaron en el preludio del inicio de la crisis de los ochenta, entre 1966 y 1982; por último, las trayectorias de los miembros de la cohorte 1966-1968 transcurrieron en su primera parte durante la crisis de los ochenta y en su culminación durante el periodo de liberalización económica de los noventa. En este sentido, el logro ocupacional a los 29 años de los miembros de cada cohorte refleja su exposición a periodos sucesivos del desarrollo socioeconómico del país.

La información longitudinal de la Eder permite bosquejar un panorama de la movilidad ocupacional intergeneracional (comparación entre la ocupación de un individuo y la de su padre) e intrageneracional (comparación entre las ocupaciones de un mismo individuo en dos momentos de su vida) de la población masculina. En este artículo analizaremos la movilidad intergeneracional, por lo que compararemos la ocupación del padre del entrevistado a los 15 años de edad con la del entrevistado a los 29 años. ${ }^{9}$

Los datos para el análisis de la movilidad ocupacional en Monterrey provienen de dos fuentes: la Encuesta sobre Movilidad Social y Geográfica en Monterrey, realizada por Browning, Balán y Jelin en 1965, y la Encuesta sobre Movilidad Social y Curso de Vida en Monterrey, que se llevó a cabo a finales del año 2000 con el propósito de hacer comparaciones adecuadas con la encuesta levantada 35 años antes. Ambas encuestas recopilaron historias ocupacionales completas de una

${ }^{8}$ La selección de las cohortes no fue arbitraria. Por un lado se optó por no entrevistar a personas de más de 65 años de edad, pues es bien conocido que los errores de memoria se incrementan de manera significativa en edades avanzadas. Por el otro, y con el fin de realizar comparaciones temporales adecuadas, se seleccionaron cohortes en las cuales las probabilidades individuales de haber iniciado el ciclo de vida familiar (primera unión y primer hijo) fueran muy altas. Por estas razones no se seleccionó a personas que al momento de la encuesta fueran menores de 30 años.

${ }^{9}$ Dado que la Eder proporciona información retrospectiva, se descartó el uso de la ocupación actual y se decidió utilizar la ocupación a los 29 años como punto de referencia fijo para todas las cohortes. Esto permite aislar el efecto de las diferencias de edad en el contraste del logro ocupacional entre las cohortes. 


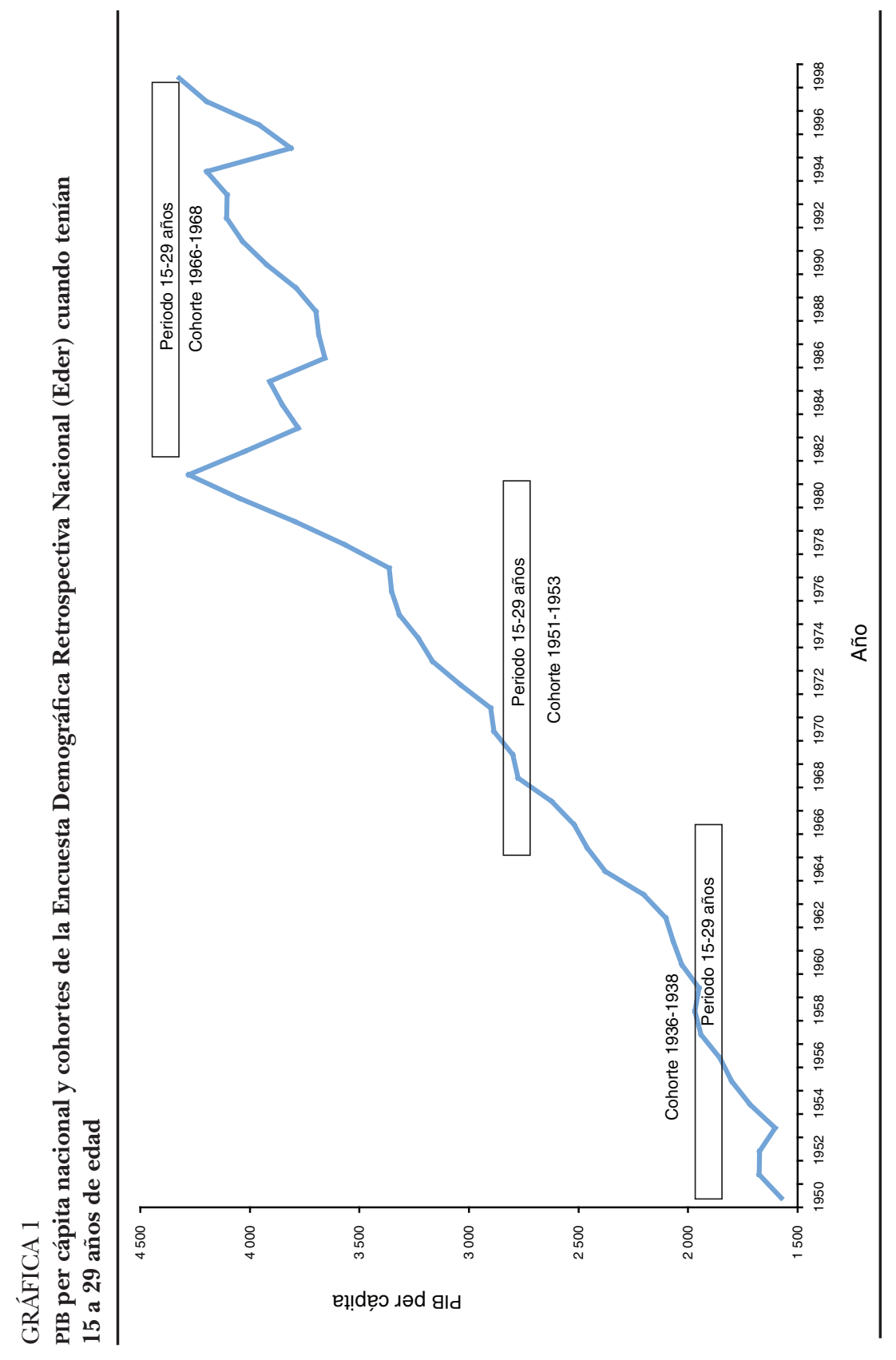


muestra de hombres adultos residentes en Monterrey, así como variables relevantes como la escolaridad, el origen migratorio, la ocupación del padre y otras características sociodemográficas.

Si bien en términos generales la Eder y las encuestas de Monterrey son muy similares, para realizar las comparaciones entre ambos contextos fue necesario tomar ciertas decisiones y adoptar algunos supuestos:

- Los mercados de trabajo rural y urbano representan condiciones laborales muy distintas, de ahí que el análisis nacional se centre sólo en la fracción urbana de la muestra nacional de la Eder, es decir, en la población que a los 29 años de edad residía en localidades de 15000 o más habitantes.

- Las cohortes de las encuestas de la ciudad de Monterrey fueron reagrupadas de tal forma que tuvieran la mayor semejanza posible con las de la Eder en aspectos tales como el número de cohortes, el espacio temporal y el tamaño de la muestra. Así, los hombres entrevistados en la ciudad de Monterrey fueron clasificados en las siguientes cohortes de nacimiento: 1925-1932, 1948-1956 y 1963-1967. Esta reagrupación de las cohortes no modifica los resultados reportados por Solís (2002).

- El análisis de la movilidad social se centra en las trayectorias individuales de la población masculina, pues no existe información semejante para las mujeres en el caso de Monterrey.

- Debido a limitaciones en las fuentes de datos no fue posible utilizar la misma edad como punto de referencia para obtener la ocupación del entrevistado, por lo que en el caso de la Eder se adoptaron los 29 años, y en el de Monterrey los 33 años.

- Dada la reducción significativa del número de casos de la Eder al trabajar sólo con las submuestras de población masculina y urbana, fue imposible trabajar con una clasificación de ocupaciones más detallada.

La clasificación ocupacional empleada es idéntica a la que propuso Solís en su trabajo original e identifica una jerarquía de cuatro grupos ocupacionales. En el rango superior están los trabajadores no manuales de alta calificación (I), seguidos por los no manuales de baja calificación (II), los trabajadores manuales de alta calificación (III), y 
por último los manuales de baja calificación (IV). ${ }^{10}$ Los trabajadores agrícolas se incluyen en este último grupo.

\section{Tablas de movilidad, movilidad estructural y asociación entre orígenes y destinos}

Antes de iniciar el análisis de las tablas de movilidad intergeneracional es conveniente revisar el "punto de partida" de las distintas cohortes, esto es, los elementos que definen el origen social de los padres. El cuadro 2 presenta información general sobre estas características socioeconómicas. Como podemos observar, el origen rural de los padres de las cohortes regiomontanas disminuyó en forma sistemática, de tal manera que sólo $16 \%$ de la generación joven tuvo padres cuyo nacimiento ocurrió en localidades rurales. Los padres de la población urbana nacional fueron actores importantes en el intenso proceso de migración rural urbana que experimentó México en la segunda mitad del siglo pasado. Así, y contrastando con Monterrey, el origen rural de los padres se incrementó $20 \%$ en números absolutos entre las cohortes avanzada e intermedia. ${ }^{11}$ Casi siete de cada diez miembros de la cohorte 1951-1953 tuvieron padres nacidos en comunidades rurales.

Entre los miembros de la cohorte joven, la proporción de padres que nació en localidades rurales disminuyó significativamente a $39 \%$. Sin embargo, esta cifra fue alta en relación con los padres de la cohorte joven de Monterrey. El origen rural de los padres de las cohortes nacionales no fue un obstáculo para que éstos se insertaran en forma exitosa en los mercados de trabajo urbanos. Al comparar las cohortes avanzadas, los padres del conjunto urbano nacional se beneficiaron de una mejor estructura ocupacional que los padres de los residentes regiomontanos; esto a pesar de la mayor presencia de padres de origen rural en el primer grupo que en el segundo.

$\mathrm{Al}$ observar la cohorte intermedia dos resultados llaman la atención. Por un lado, las oportunidades ocupacionales de los padres mejoraron de manera notable en Monterrey, mientras que en el ámbito nacional hubo pocos cambios. No obstante, la estructura ocupacional de los padres siguió siendo favorable a la población urbana

${ }^{10}$ Para una descripción más detallada véase Solís, 2002.

${ }^{11}$ Los términos avanzada, intermedia y joven hacen referencia, respectivamente, a las cohortes 1936-1938, 1951-1953 y 1966-1968 de la Eder, y 1925-1932, 1948-1956 y 1963-1967 de Monterrey. 


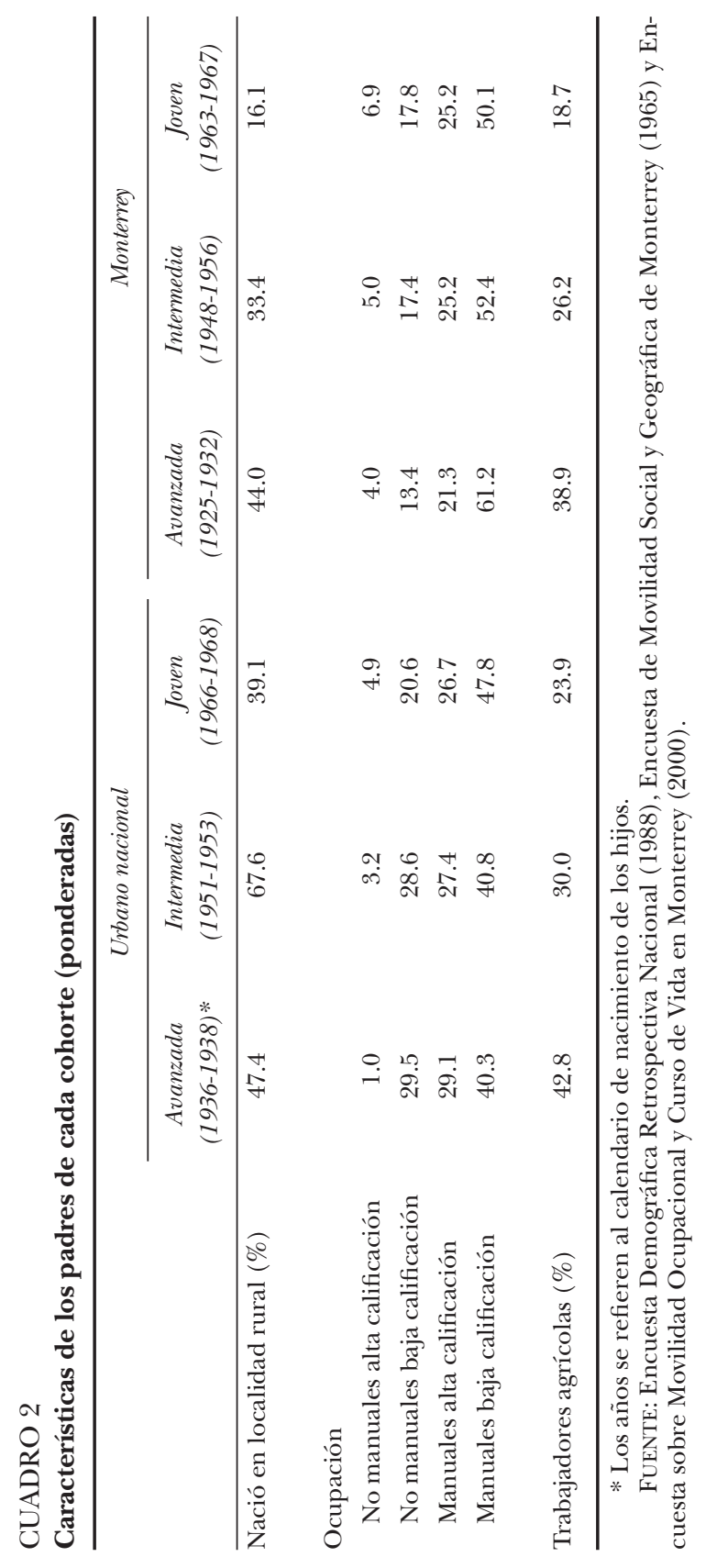


nacional. Por el otro, la continuidad de la estructura ocupacional entre los padres de las generaciones avanzada e intermedia a escala nacional debe evaluarse de manera positiva dado el incremento de la migración rural urbana. Es decir, si bien la proporción de padres inmigrantes rurales se incrementó en la cohorte intermedia, esto no se reflejó en un deterioro de sus oportunidades ocupacionales, lo que refleja que los inmigrantes rurales tuvieron mayores oportunidades de movilidad ascendente, particularmente porque lograron mantener una inserción significativa en ocupaciones no manuales de baja calificación.

Mientras las oportunidades ocupacionales de los padres de la generación joven regiomontana continuaron siendo prácticamente las mismas que las de la generación anterior, las correspondientes al contexto urbano nacional sufrieron un deterioro importante. Los padres de la cohorte joven nacional (con orígenes más urbanos que sus antecesores) experimentaron una reducción significativa de su acceso a ocupaciones no manuales de baja calificación, mientras que aumentaron su inserción en el trabajo manual de baja calificación. ${ }^{12}$ Todo parece indicar que los padres de la generación 1966-1968 del conjunto urbano nacional fueron los primeros en resentir un agotamiento de las oportunidades ocupacionales que ofrecían las ciudades a los migrantes rurales. ${ }^{13}$ Estos cambios condujeron a una mayor convergencia entre las estructuras ocupacionales nacionales y regiomontanas.

En resumen, a pesar de que una mayor proporción de los padres de las cohortes nacionales contaba con antecedentes rurales en relación con los de Monterrey, los primeros encontraron mejores oportunidades ocupacionales que los segundos. Una posible explicación a este fenómeno es el impresionante auge económico y social que experimentó la Ciudad de México durante los años cincuenta y sesenta. En las cohortes avanzada e intermedia la distribución de los padres se concentró más en ocupaciones manuales de baja calificación en Monterrey que en el contexto urbano nacional. Esta diferencia prácticamente desapareció entre los padres de la cohorte joven, principalmente como consecuencia del deterioro de la estructura ocupacional de los padres de la cohorte joven nacional, lo cual podría estar asociado a un incremento relativo del empleo industrial de baja calificación. Así, la pro-

${ }^{12}$ Como puede apreciarse en el cambio, esto no se debe a un incremento del trabajo agrícola, sino más bien a un aumento de las ocupaciones de baja calificación urbanas.

${ }^{13}$ No debemos soslayar que casi 4 de 10 padres de esta cohorte habían nacido en localidades rurales. 
porción de individuos cuyo padre tuvo una ocupación no manual de baja calificación en la cohorte joven es similar en ambos contextos (47.8\% en el nacional urbano frente a $50.1 \%$ en Monterrey).

Los cambios descritos son importantes para comprender la movilidad intergeneracional. El cuadro 3 muestra las tablas de movilidad ocupacional intergeneracional para las tres cohortes nacionales urbanas y de Monterrey. Estas tablas permiten obtener las medidas resumen de movilidad ocupacional que aparecen en el cuadro 4. Los resultados que se presentan en ambos cuadros llevan a concluir lo siguiente:

a) En ambos contextos y en todas las cohortes la distribución ocupacional de los miembros de cada cohorte (hijos) fue mejor que la correspondiente a sus padres. Además, las oportunidades ocupacionales de los hijos mejoraron a través del tiempo, particularmente en el contexto urbano nacional.

b) Si bien las oportunidades ocupacionales de los padres fueron mejores o semejantes en el contexto urbano nacional que en Monterrey, lo contrario prevaleció en la estructura ocupacional de los hijos, con la excepción de las cohortes avanzadas,_donde existió una ligera diferencia a favor de los hijos del conjunto nacional urbano. Sin embargo, a partir de la cohorte intermedia las oportunidades ocupacionales fueron más favorables para la población de Monterrey, particularmente debido a su inserción en trabajos no manuales. En la cohorte joven, por ejemplo, la proporción de trabajadores en ocupaciones no manuales fue de $52 \%$ en Monterrey y de $46 \%$ en el conjunto urbano del país.

c) Las diferentes tendencias entre padres e hijos produjeron cambios importantes en la movilidad estructural de ambos contextos. ${ }^{14}$ En las cohortes avanzada e intermedia Monterrey experimentó tasas de movilidad estructural que duplicaron las observadas en el contexto nacional urbano (25\% frente a 12 o $13 \%)$. Como puede apreciarse al revisar las distribuciones marginales del cuadro 3, en estas dos cohortes la mayor movilidad estructural de Monterrey se explica básicamente por la

${ }^{14}$ La movilidad estructural se obtiene al calcular el índice de disimilitud entre las distribuciones marginales de padres e hijos, y puede interpretarse como el volumen de movilidad intergeneracional que se genera por el cambio en las estructuras ocupacionales de origen y destino. Este cambio suele asociarse en buena medida a las transformaciones globales en la estructura del mercado de trabajo (Solís, 2002). 
mayor proporción de hijos de trabajadores manuales de baja calificación, y en menor medida por un "ajuste hacia arriba" en las distribuciones ocupacionales de los entrevistados. En otras palabras, a pesar de que los padres de las cohortes avanzada e intermedia regiomontanas tuvieron oportunidades ocupacionales más restringidas que los padres de las mismas cohortes nacionales, los primeros encontraron en Monterrey condiciones económicas y sociales más propicias para heredar mejores posiciones laborales a sus hijos.

d) La comparación de las cohortes jóvenes es un poco más complicada. En primer lugar, ambas cohortes experimentaron un incremento en la movilidad estructural. A pesar de que el incremento relativo de la movilidad estructural en comparación con la cohorte intermedia fue mayor en el conjunto urbano nacional que en Monterrey, la ciudad norteña continuó teniendo una mayor movilidad estructural que la nacional urbana (32 y $25 \%$ respectivamente). Por otro lado, el despunte de la movilidad intergeneracional a escala nacional estuvo asociado no sólo con la existencia de mejores oportunidades ocupacionales de los hijos, sino también con un deterioro de la estructura ocupacional de sus padres (asociado principalmente con una disminución de las ocupaciones no manuales de baja calificación y un aumento en las ocupaciones manuales de baja calificación).

En lo que respecta a las tasas de movilidad que se obtienen al considerar la distribución de casos al interior de la tabla, puede observarse lo siguiente:

a) En las tres cohortes el conjunto urbano nacional presentó tasas de movilidad más altas que Monterrey, aunque las diferencias no son cuantiosas. En la cohorte avanzada, las tasas de inmovilidad para el contexto urbano nacional fueron de $42 \%$, frente a $49 \%$ en Monterrey; en la cohorte intermedia fueron 34 y $40 \%$, y en la cohorte joven 32 y $39 \%$, respectivamente.

b) La mayor movilidad intergeneracional tiene un doble rostro en el contexto urbano del país. Por un lado, en todas las cohortes existieron contingentes importantes de hijos que experimentaron un descenso ocupacional en comparación con sus padres. La cifra más alta fue en la cohorte intermedia en don- 
de casi uno de cada cuatro miembros sufrieron un descenso social. La movilidad descendente fue siempre más alta en el ámbito nacional que en Monterrey. Por el otro, la movilidad ascendente fue en aumento en el contexto nacional, al igual que en Monterrey. Sin embargo, Monterrey siempre mantuvo altas tasas de movilidad social ascendente.

Los resultados anteriores permiten concluir lo siguiente. Los padres de las cohortes analizadas encontraron mejores condiciones de empleo en el conjunto de localidades urbanas del país que en Monterrey, especialmente a la luz de sus importantes antecedentes rurales. Sin embargo, la gran movilidad social que la migración rural urbana representó para los padres del conjunto nacional urbano no se transmitió en una forma tan amplia hacia sus hijos como ocurrió en Monterrey. Las oportunidades sociales y económicas que ofreció Monterrey durante la segunda mitad del siglo Xx permitieron a los hijos mantenerse o avanzar en su estatus socioeconómico. En México la existencia de una mayor movilidad social intergeneracional estuvo asociada no sólo con posibilidades de ascender socialmente, sino también de descender en la estructura de clases. Si bien las diferencias en la movilidad ocupacional de Monterrey y el conjunto urbano del país se cerraron entre la población más joven, esto se debió en gran medida a que los padres de la cohorte nacional sufrieron un deterioro en sus oportunidades ocupacionales.

Finalmente, los datos revelan que la población joven que entró al mercado de trabajo durante los años de reestructuración y crisis económicas continuó experimentando una movilidad intergeneracional ascendente significativa tanto en el ámbito nacional urbano como en Monterrey. Sin embargo, es importante aclarar que esta movilidad ascendente no se debió al crecimiento de las oportunidades en ocupaciones no manuales de alta calificación (profesionistas o técnicos especializados), sino más bien a la expansión del empleo no manual de baja calificación (especialmente vendedores y comerciantes) y manual calificado. 


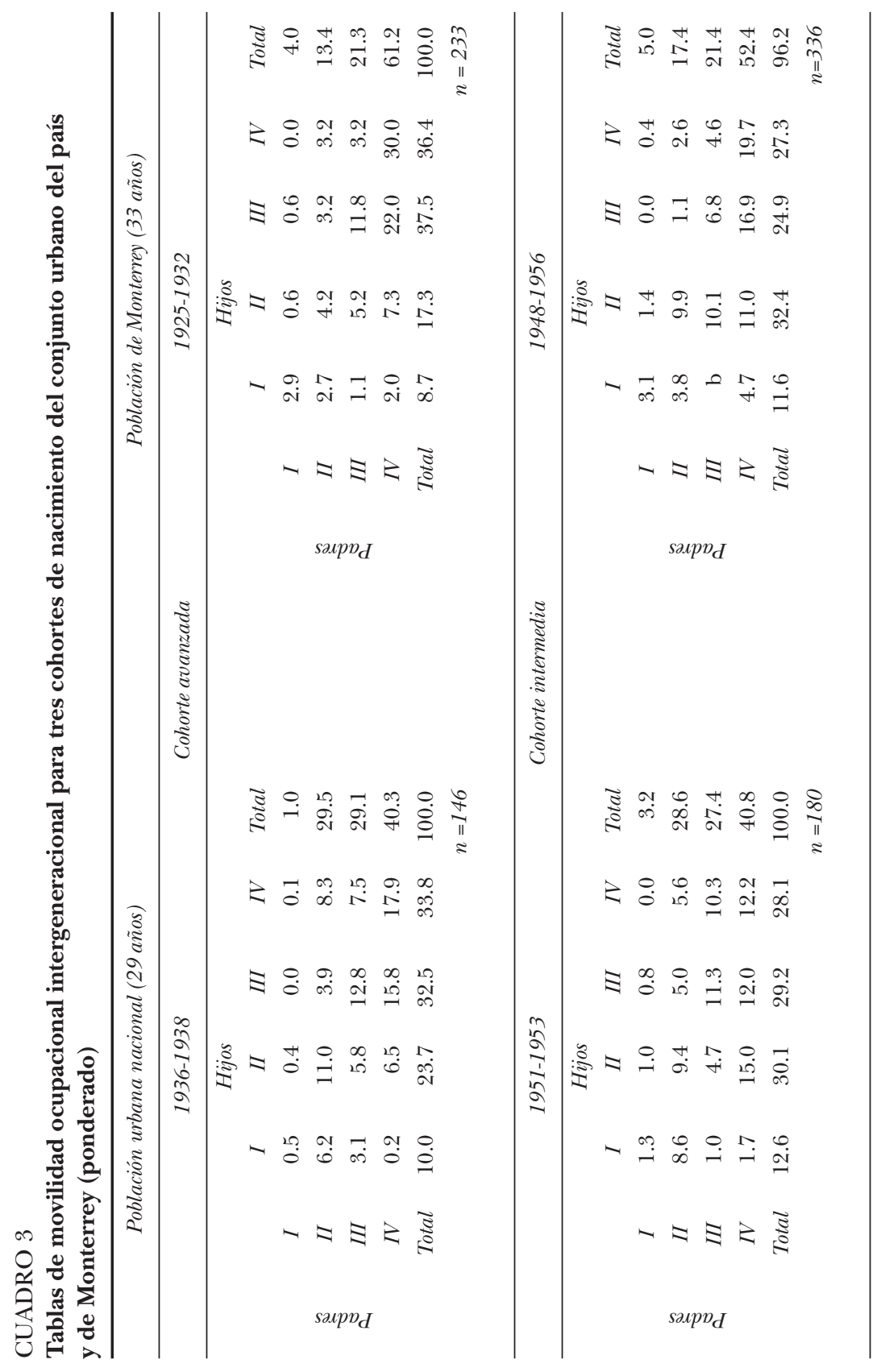




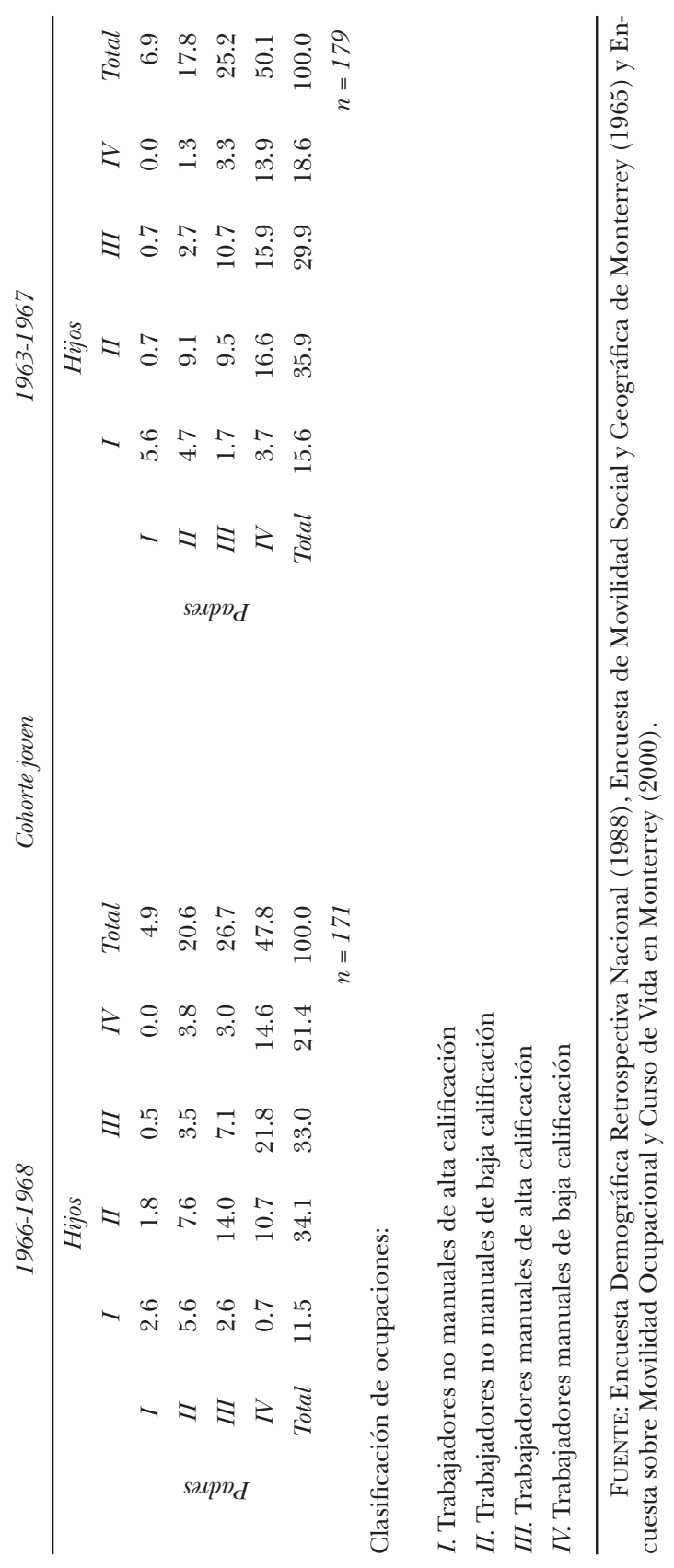


CUADRO 4

Medidas resumen de movilidad ocupacional (ponderadas)

\begin{tabular}{|c|c|c|}
\hline & \multicolumn{2}{|c|}{ Cohorte avanzada } \\
\hline & $\begin{array}{c}\text { Urbano nacional } \\
(1936-1938)\end{array}$ & $\begin{array}{c}\text { Monterrey } \\
(1925-1932)\end{array}$ \\
\hline Movilidad estructural & 12 & 25 \\
\hline \multicolumn{3}{|c|}{ Movilidad en el interior de la tabla } \\
\hline Movilidad ascendente & 38 & 40 \\
\hline Movilidad descendente & 20 & 11 \\
\hline Sin movilidad & 42 & 49 \\
\hline \multirow[t]{3}{*}{ Total } & 100 & 100 \\
\hline & \multicolumn{2}{|c|}{ Cohorte intermedia } \\
\hline & $\begin{array}{c}\text { Urbano nacional } \\
\text { (1951-1953) }\end{array}$ & $\begin{array}{c}\text { Monterrey } \\
(1948-1956)\end{array}$ \\
\hline Movilidad estructural & 13 & 25 \\
\hline \multicolumn{3}{|c|}{ Movilidad en el interior de la tabla } \\
\hline Movilidad ascendente & 43 & 50 \\
\hline Movilidad descendente & 23 & 10 \\
\hline Sin movilidad & 34 & 40 \\
\hline \multirow[t]{3}{*}{ Total } & 100 & 100 \\
\hline & \multicolumn{2}{|c|}{ Cohorte joven } \\
\hline & $\begin{array}{c}\text { Urbano nacional } \\
\text { (1966-1968) }\end{array}$ & $\begin{array}{c}\text { Monterrey } \\
(1963-1967)\end{array}$ \\
\hline Movilidad estructural & 26 & 32 \\
\hline \multicolumn{3}{|c|}{ Movilidad en el interior de la tabla } \\
\hline Movilidad ascendente & 55 & 52 \\
\hline Movilidad descendente & 13 & 9 \\
\hline Sin movilidad & 32 & 39 \\
\hline Total & 100 & 100 \\
\hline
\end{tabular}

FuENTE: Encuesta Demográfica Retrospectiva Nacional (1988), Encuesta de Movilidad Social y Geográfica de Monterrey (1965) y Encuesta sobre Movilidad Ocupacional y Curso de Vida en Monterrey (2000). 


\section{Logro ocupacional y origen social: ¿̇mayor inequidad en las oportunidades?}

¿Qué importancia tiene el origen social de los individuos para explicar su logro ocupacional? ¿Al igual que en Monterrey, es posible concluir que existe en el contexto urbano nacional una tendencia hacia una mayor inequidad de las oportunidades ocupacionales? Para dar respuesta a estas preguntas optamos por construir modelos de regresión logística ordenada (Powers y Xie, 2000). Estos modelos permiten contrastar el riesgo de que un individuo de origen social $x_{1}$ (v.g. ocupación del padre) logre una ocupación de mayor jerarquía que otro con origen social "de referencia" $x_{2}$, una vez que se controla la movilidad estructural y se toman en cuenta los efectos del resto de las variables incluidas en el modelo. El riesgo diferencial de los modelos de regresión logística ordenados es expresado por las "razones de momios" (odds ratios). Si el valor estimado de la razón de momios no varía significativamente de 1 , entonces no hay diferencias en el logro entre quienes tienen un estrato de origen $x_{1}$ y $x_{2}$. Si la razón de momios es significativamente mayor que 1 , entonces la probabilidad de logro mayor es para el estrato $x_{1}$. Por el contrario, si la razón de momios es significativamente menor que 1 , entonces la probabilidad de logro es mayor para el estrato $x_{2}$.

El cuadro 5 muestra los resultados de los dos modelos que fueron calculados para cada una de las cohortes. ${ }^{15}$ El modelo 1 introduce dos variables asociadas a los orígenes sociales: la "ocupación del padre", ${ }^{16}$ que es un indicador del estrato social de origen del individuo, y la "comunidad de origen", que distingue a quienes fueron socializados en comunidades rurales de quienes pasaron la mayor parte de su niñez y adolescencia en entornos urbanos. ${ }^{17}$ En este modelo los efectos del estrato social de origen se pueden interpretar como si fueran indepen-

${ }^{15}$ Una estrategia alternativa al ajuste de modelos independientes por cohorte es plantear un modelo único en donde se incluya la interacción entre la cohorte y las variables de orígenes sociales y de escolaridad. No obstante, dado que nuestro interés era establecer si en cada cohorte las diferencias entre estratos sociales eran estadísticamente significativas, optamos por ajustar modelos independientes por cohorte, que permiten poner a prueba directamente esa hipótesis.

${ }^{16}$ Quienes tenían padres en ocupaciones no manuales de alta y baja calificación fueron agrupados en una sola categoría ("no manual"), debido al reducido tamaño de la muestra.

${ }^{17}$ La comunidad de origen se obtiene a partir de la historia residencial del individuo, y es el tamaño de comunidad en donde el individuo pasó más tiempo cuando tenía entre 5 y 15 años de edad. 


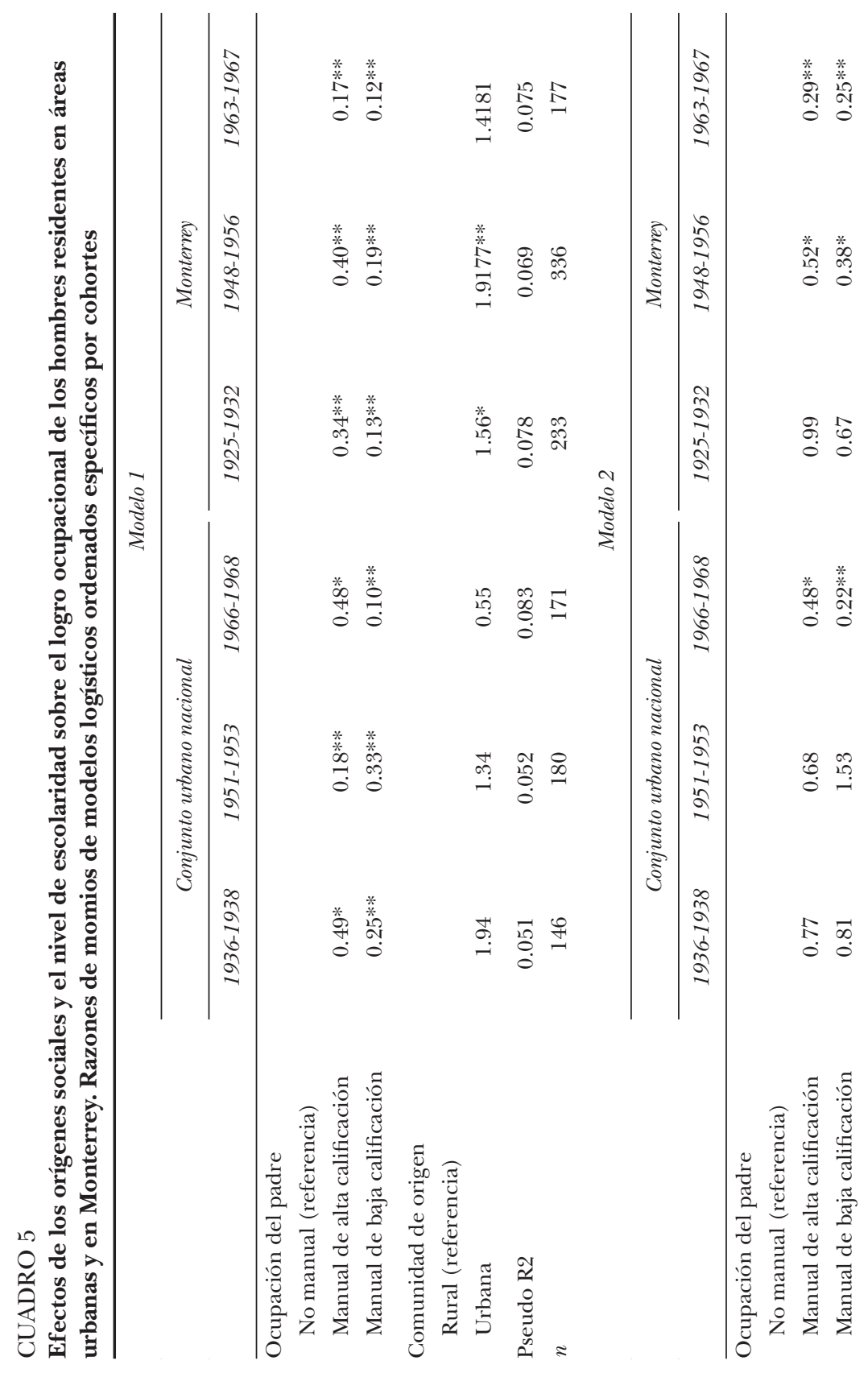




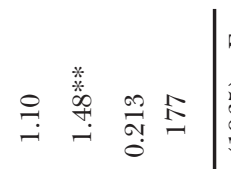

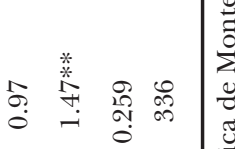

$$
\begin{aligned}
& \text { - } \rightarrow \text { बु }
\end{aligned}
$$

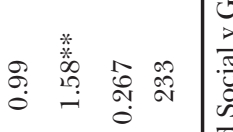

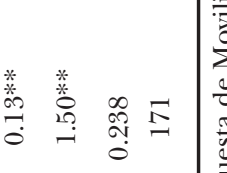

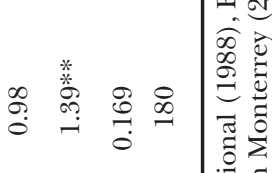

$$
\begin{aligned}
& \text { * } \\
& \text { 今. }
\end{aligned}
$$

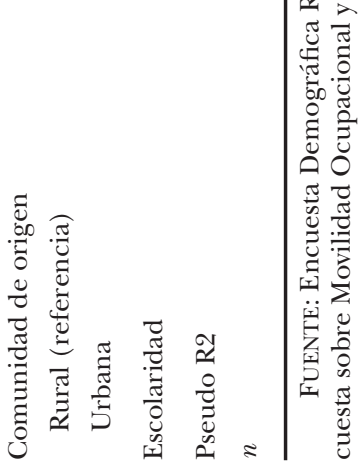


dientes del origen migratorio. El modelo 2 incluye, además de las dos variables anteriores, el nivel de escolaridad del individuo. Desde la perspectiva del capital humano, la escolaridad y la experiencia laboral deberían ser los principales mediadores entre los individuos y la estructura de oportunidades ocupacionales con el fin de ascender socialmente. Al introducir la escolaridad se está en condiciones de estimar el efecto neto del estrato de origen sobre el logro ocupacional.

Los resultados para las cohortes de Monterrey son simplemente una confirmación de lo encontrado por Solís (2002). Esto es, la escolaridad ejerce en todas las cohortes una fuerte influencia sobre el logro ocupacional. Aunque el efecto de la ocupación del padre disminuye cuando se toma en consideración el nivel de escolaridad de la persona, el estrato de origen se mantiene como un determinante significativo del logro ocupacional. Las diferencias en el logro ocupacional entre quienes provienen de orígenes sociales relacionados con ocupaciones manuales (tanto de alta como de baja calificación) y ocupaciones no manuales, pasaron de ser no significativas en la primera cohorte a ser significativas en los más jóvenes. Por lo tanto, en el caso de Monterrey, una vez controlados los efectos del nivel de escolaridad, la desigualdad por estrato de origen en las oportunidades laborales se incrementó en el tiempo, en lugar de decrecer.

¿Qué sucedió en el contexto nacional urbano? Sin tomar en consideración las diferencias en los niveles de escolaridad de la población masculina, los resultados del modelo 1 muestran que en las tres cohortes el origen social tiene efectos significativos sobre el logro ocupacional. En la cohorte avanzada, los momios de lograr una mejor ocupación para los trabajadores manuales de alta y baja calificación eran 51 y $75 \%$ menores, respectivamente, en relación con los trabajadores no manuales. En la cohorte intermedia esta diferencia fue de 82 y $67 \%$, y en la cohorte joven de 52 y $90 \%$. Cabe destacar que la inequidad de oportunidades entre los trabajadores manuales de baja calificación y los no manuales fue significativamente mayor en la cohorte joven, es decir, en aquella cuya trayectoria laboral transcurrió enteramente durante los años de crisis y cambio estructural.

La escolaridad desempeñó un papel significativo en el logro ocupacional de la población masculina del país durante la segunda mitad del siglo pasado. La propensión a ascender socialmente vía la estructura ocupacional se incrementaba entre 39 y $50 \%$ por cada año que se avanzaba en el ciclo escolar. Como puede apreciarse en la parte inferior del cuadro 5, el efecto de la variable escolaridad fue notoriamente 
inferior en el conjunto nacional que en Monterrey para las cohortes avanzada e intermedia, pero adquiere dimensiones similares (alrededor de $50 \%$ ) en la cohorte joven. En otras palabras, y una vez que se controlan los orígenes sociales, el conjunto urbano nacional ofrecía menores retribuciones al logro escolar que Monterrey durante los años de auge y ocaso de la sustitución de importaciones, pero en tiempos recientes estas retribuciones se incrementaron a un nivel similar al observado en la capital nuevoleonesa.

Si bien la instrucción formal de las personas contribuye a entender mejor el logro ocupacional de los individuos de todas las cohortes, los efectos del origen social no desaparecieron en la cohorte joven. Al igual que en Monterrey, la importancia creciente del estrato social de origen queda comprobada por las categorías ocupacionales extremas de esta cohorte. En la cohorte 1965-1968 los momios de lograr una mejor ocupación fueron 4.5 veces menores para los hijos de trabajadores manuales con baja calificación en comparación con los hijos de trabajadores no manuales. Por su parte, los hijos de trabajadores manuales no calificados contaban con la mitad de los momios de ascender socialmente respecto a los pertenecientes a la categoría de referencia.

\section{Conclusiones}

Las ciencias sociales en México parecen retomar las preocupaciones centradas en los efectos del desarrollo económico y social más reciente sobre la desigualdad social en el curso de vida de su población. En este trabajo hemos intentando dilucidar las tendencias recientes de dos aspectos centrales de la estratificación social: la capacidad de ascender socialmente en la estructura de oportunidades ocupacionales, y la influencia del origen social en dicho logro ocupacional. Nuestro análisis se centró en la movilidad intergeneracional que ha experimentado la población masculina residente en las localidades urbanas del país durante la segunda mitad del siglo pasado.

Los datos de la Eder permitieron demostrar que la economía y la sociedad mexicanas fueron capaces de promover la movilidad ocupacional intergeneracional ascendente durante la segunda mitad del siglo pasado. Las amplias posibilidades de movilidad ocupacional se reflejaron en las oportunidades laborales que tuvieron los propios padres, pues fueron capaces de insertarse en una estructura ocupacional cada vez más favorable, a pesar de que gran proporción de ellos contaba 
con antecedentes rurales. Aunque el sistema urbano del país fue capaz de ofrecer también movilidad ocupacional a sus descendientes, la información muestra que Monterrey pudo favorecerlos de manera más extensa y sostenida. Mientras que la estructura económica y social regiomontana posibilitó ampliamente la mejora de las condiciones ocupacionales de los hijos, esta mejora no fue tan extensa ni permanente en el contexto urbano nacional, en donde incluso se observa una mayor polarización de la movilidad ocupacional al presentarse mayores tasas de movilidad descendente. Las diferencias entre la movilidad ocupacional de Monterrey y la del conjunto urbano del país se redujeron en la cohorte más joven. Sin embargo esta convergencia se debió en gran medida al deterioro de las oportunidades ocupacionales de los padres en el conjunto urbano nacional, y no a una mejora en las condiciones de los hijos. Si bien sería necesario estudiar con más profundidad este deterioro en el estatus ocupacional de los padres, una hipótesis plausible es que se trata de la primera cohorte en que los inmigrantes rurales enfrentaron problemas para incorporarse exitosamente al mercado laboral urbano.

Por otro lado, si bien la información revela que los jóvenes que ingresaron al mercado de trabajo durante los años de reestructuración y crisis económicas continuaron experimentando una movilidad intergeneracional ascendente en el ámbito urbano nacional, incluyendo Monterrey, es importante aclarar que este proceso tuvo muy poco que ver con el crecimiento de ocupaciones no manuales de alta calificación (profesionistas o gerentes); más bien fue el resultado de una expansión del empleo no manual de baja calificación (grupo en el que se encuentran los comerciantes y los vendedores) y de las ocupaciones manuales calificadas. En este sentido queda pendiente revisar hasta qué punto la nueva movilidad ocupacional ascendente se traduce efectivamente en una mejora en las condiciones laborales y por tanto en movilidad social ascendente. Los datos de la Eder no permiten profundizar en esta hipótesis, pero la investigación de Solís para Monterrey sugiere que, a diferencia de lo que ocurría durante la sustitución de importaciones, en tiempos recientes la movilidad ocupacional ascendente ya no garantiza la movilidad ascendente en otros ámbitos, como el del ingreso.

Finalmente, los resultados muestran que al igual que en Monterrey, el estrato social de origen, medido por la ocupación del padre, tiene una creciente importancia como determinante del logro ocupacional de los hombres del conjunto urbano nacional. Este efecto permanece 
incluso una vez que se controla el efecto de la escolaridad, que conservó un papel significativo en el logro ocupacional de la población masculina del país durante la segunda mitad del siglo pasado. En su conjunto, estos resultados muestran un panorama poco alentador, pues indican que a pesar del incremento en las tasas de movilidad absoluta, la inequidad social en el acceso a las oportunidades laborales es de igual o mayor magnitud que la observada durante el periodo de sustitución de importaciones. En este sentido, la aspiración a futuro no es sólo incrementar las oportunidades para una mayor y más efectiva movilidad ocupacional ascendente, sino generar las condiciones estructurales e institucionales que favorezcan una distribución más equitativa de estas oportunidades entre los jóvenes provenientes de distintos estratos sociales.

\section{Bibliografía}

Balán, J., H. Browning y E. Jelin (1977), El hombre en una sociedad en desarrollo. Movilidad geográfica y social en Monterrey, México, Fondo de Cultura Económica.

Blossfeld, H. y G. Rohwer (2002), Techniques of Event History Modeling New Approaches to Causal Analysis, Mahwah, Lawrence Erlbaum Associates.

Behrman, J., A. Gaviria y M. Székely (2001), "Intergenerational Mobility in Latin America", Economia. Journal of the Latin American and Caribbean Economic Association, vol. 2, núm. 1, pp. 1-44.

Contreras, E. (1978), Estratificación y movilidad social en la Ciudad de México, México, Instituto de Investigaciones Sociales, UNAM.

Cortés, F. y A. Escobar (2003), "Movilidad social intergeneracional en los años de reforma económica: un estudio del México urbano", Revista de la CEPAL, núm. 85, pp. 149-167.

Coubes, M., M. E. Zavala y R. Zenteno (eds.) (2005), Cambio demográfico y social en el México del siglo XX. Una perspectiva de historias de vida, México, Colef/ ITESM/ Porrúa.

Escobar, A. (2001), "Nuevos modelos económicos: ¿nuevos sistemas de movilidad social?”, Santiago, División de Desarrollo Social, CEPAL (Políticas Sociales, 50).

Muñoz, H, O. de Oliveira y C. Stern (1977), Migración y desigualdad social en la Ciudad de México, México, Instituto de Investigaciones Sociales, UnAM.

Pacheco, E. (2005), "La movilidad ocupacional de los hijos frente a los padres", en Marie-Laure Coubés, Ma. Eugenia Zavala y René Zenteno (coords.), Cambio demográfico y social en México en el siglo XX. Una perspectiva de historias de vida, México, Cámara de Diputados/EGAP-Tecnológico de Monterrey/ El Colegio de la Frontera Norte/Miguel Ángel Porrúa, pp. 227-258. 
Parrado, E. (2005), "Economic Restructuring and Intra-generational Class Mobility in México", Social Forces, vol. 84, núm. 2, pp. 733-757.

Powers, D. e Y. Xie (2000), Statistical Methods for Categorical Data Analysis, California, Academic Press.

Solís, P. (2005), "Cambio estructural y movilidad ocupacional en Monterrey, México”, Estudios Sociológicos, vol. 23, núm. 1 (67), pp. 43-74.

- (2002), Structural Change and Men's Work Lives: Transformations in Social Stratificatrion and Occupational Mobility in Monterrey, Mexico, tesis de doctorado en Sociología, Universidad de Texas en Austin.

Tuma, N. B. y M. T. Hannan (1984), Social Dynamics. Models and Methods, Orlando, Academia Press.

Zenteno, R. (2003), "Polarización de la movilidad social en México", Demos. Carta Demográfica Sobre México, núm. 16. 